\title{
USE OF MANEUVERABLE PROPERTIES OF HYDROELECTRIC POWER PLANTS AND HYDRO-ACCUMULATING POWER PLANTS FOR IMPROVING RELIABILITY AND OPERATING EFFICIENCY OF ELECTRIC POWER SYSTEMS OF COMMONWEALTH COUNTRIES (USING EXAMPLE OF POWER PLANTS OF RUSSIA AND THE REPUBLIC OF UZBEKISTAN)
}

\author{
Yu.S. Vasilyev ${ }^{1}$, V.V. Elistratov ${ }^{1}$, I.G. Kudryasheva ${ }^{1}$, M.M. Mukhammadiyev ${ }^{2}$, B.U. Urishev ${ }^{3}$. \\ ${ }^{1}$ St. Petersburg Polytechnic University Peter the Great, Russia \\ ${ }^{2}$ Tashkent state technical university, 2 Universitet street Tashkent, Uzbekistan \\ ${ }^{3}$ Karshi engineering institute, 225 Mustaqillik street Karshi, Uzbekistan
}

\begin{abstract}
The possibilities of using shunting properties of HPP units, HAPS (Hydro-accumulating power system) for energy storage and redistribution, as well as Pump Station as a consumer of the regulator in night load dips to increase the reliability of the electric power system (EPS) in the conditions of the current increase in the share of non-nondestructive capacities in Russia and Uzbekistan and the implementation of programs for the development of renewable energy sources, primarily the construction of wind and solar power plants, were considered.
\end{abstract}

\section{Introduction}

The electric power system (EPS) as a production facility has a number of characteristics, the most important of which is that the process of electricity production is fundamentally different from any other production process. This difference lies in the fact that in the energy sector, the cycle of energy production, distribution and consumption is carried out simultaneously. Therefore, no change in electricity generation can be made without a corresponding change in demand for it from consumers, the readiness of high-voltage power lines and distribution networks to bring electricity to consumers.

The most important challenge for the operation of the EPS was the maximum efficient redistribution of the energy produced, i.e. the harmonization of the schedule of electricity generation and consumption at different time intervals. The process of consumption (load schedule) is uneven depending on the rhythm of a person's life, the nature of consumption, etc. One of the most important ways to improve the reliability and mode controllability of the EPS is efficient redistribution and accumulation of produced energy.

In the global practice of operating large EPS, the solution to the problem of uneven consumption of electricity is achieved by the creation of special maneuverable power equipment (peak power plants, gas turbine power plants), or by the use of storage systems (Nuclear Power Plants) that consume electricity during periods of general load reduction in EPS and deliver it during periods of increased consumption [1-9].

Currently, the Russian electricity complex includes 846 power plants with a capacity of more than $5 \mathrm{MW}$ each. As of January 1, 2020, the total installed capacity of power plants of the UES of Russia amounted to 246.3 $\mathrm{GW}$, and the production of electric energy 1080.6 TV hertz per year [10]. The separation by installed capacity and power generation of various types of power plants of the Russian Federation is given in Fig. 1. [10]. The main part of the energy balance is low-mannered thermal and nuclear power plants, while the share of the latter has been increasing in recent years. In addition, the Renewable Energy Development (Renewable Energy) Programme had been launched in 2013, which provided for the construction of more than $5.5 \mathrm{GW}$ of wind and solar power by 2024 [5]. It also makes it necessary to create additional capacities of NPP.

In the Republic of Uzbekistan, the structure of the capacity of power plants and the shares in electricity production of various types of power plants at the beginning of 2020 are presented in Fig. 2 .

The experience of foreign power plants with the predominance of small-manned power plants and the development of renewable energy shows that the share of all types of highly maneuverable plants should be at least $25 \%$ of the total installed capacity of power systems. 
a)

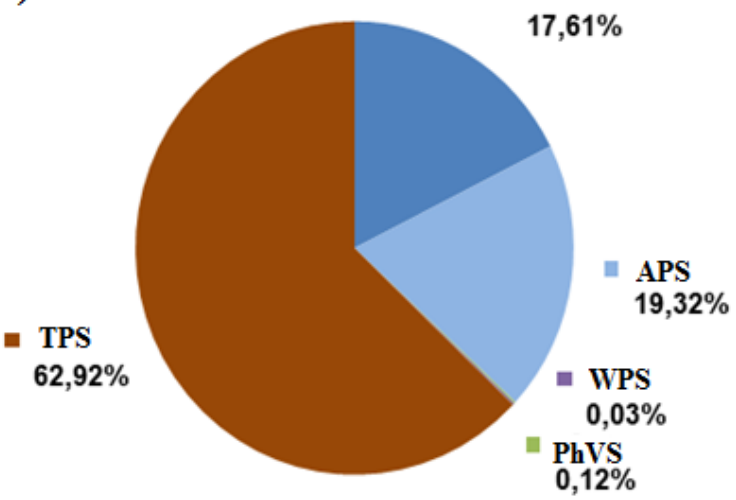

b)

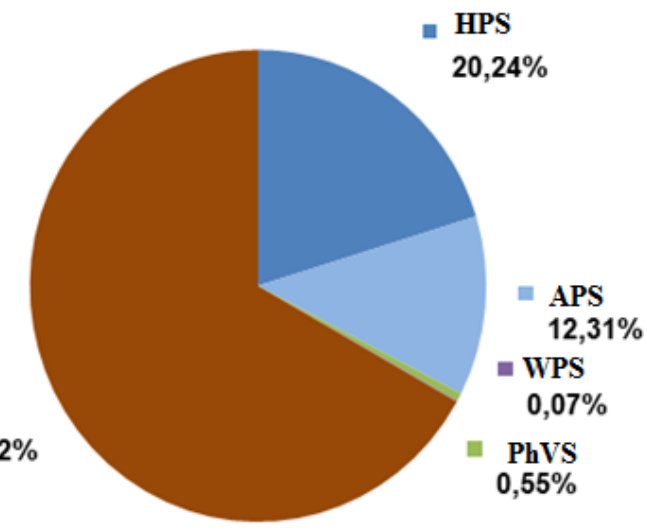

Fig. 1. Structure of power generation (a), and installed capacity of power plants of EPS of Russia, $\%$ (as of 01.01.2020)

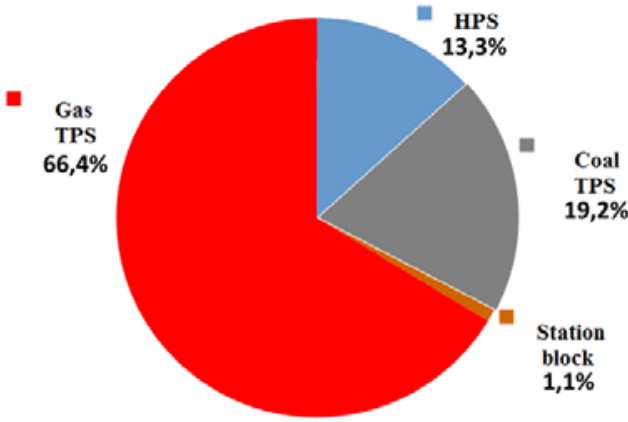

b)

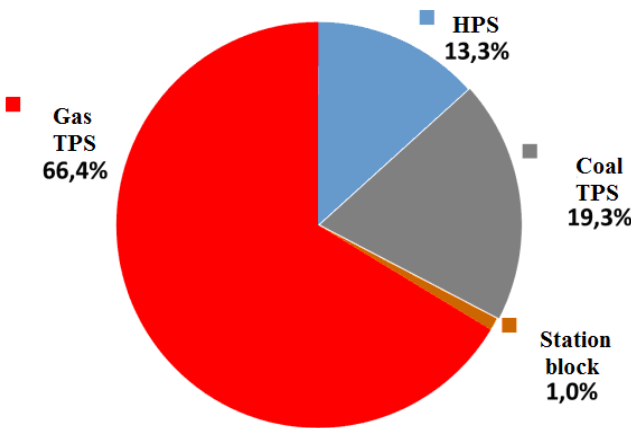

Fig. 2. Structure of power production (a), and rated capacity of power plants of EPS of Uzbekistan, $\%$ (for 01.01 .2020 )

In accordance with the Program for the Development of the Electricity Industry of Uzbekistan, by 2030 , it is planned to commission nuclear power facilities and renewable energy facilities with a share of $30 \%$ in electricity production (Fig.3), as a result of which the share of mobile hydroelectric power plants in energy production will decrease to $10.8 \%$.

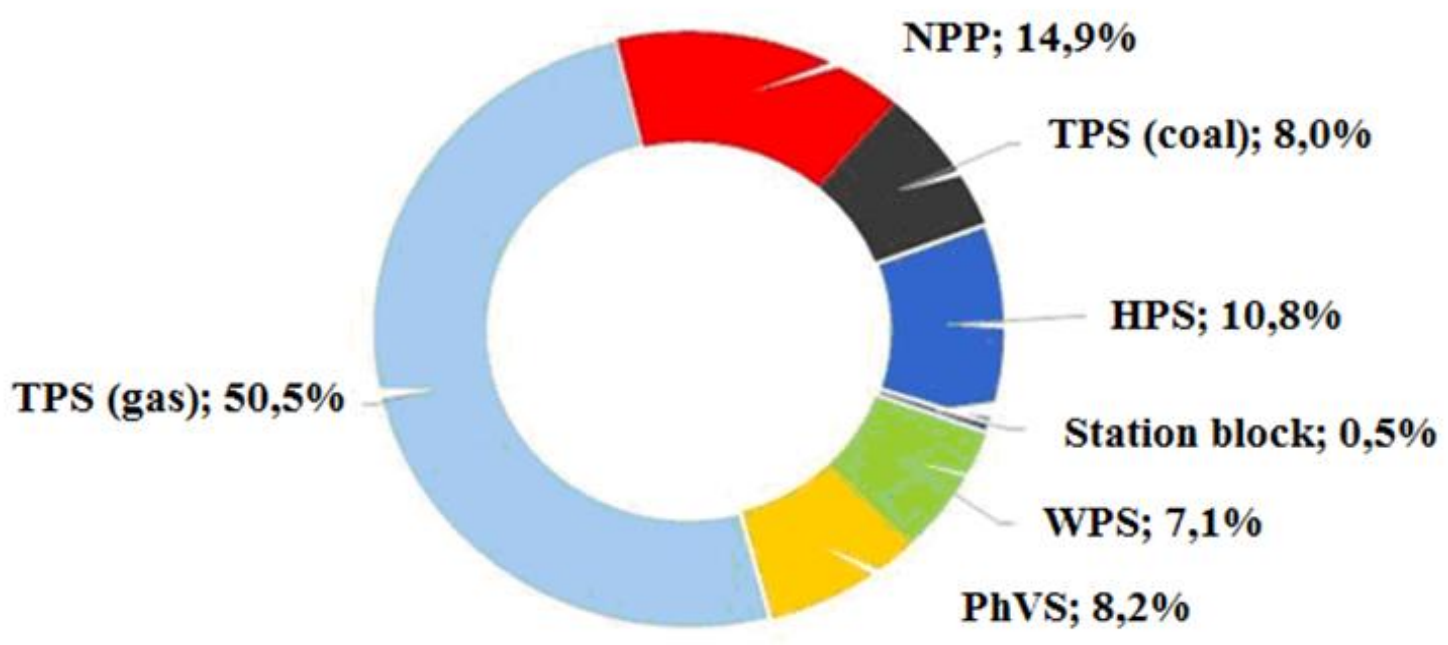

Fig. 3. Structure of power generation in Uzbekistan in 2030 (Source: Ministry of Energy of the Republic of Uzbekistan)

At the same time, in order to organize the optimal and reliable operation of the energy system, the share of HAPS (taking into account their ability to implement double regulation - both generation and load) should be $10 \ldots 12 \%$ [9.11.14]

The functions of the storage system (NPP), including HAPS in an electric power system with a 
large share of low-level power plants and RES-based plants can be the following $[5,17,18]$ : 1) leveling of structural features of the composition of power plants in the EPS; 2) daily and short-term (planned and physical) redistribution of energy in the consumption and production of energy for quality energy supply; 3 ) operational adjustment of power and maintenance of the rated frequency of current and voltage in the power system 4) formation of reserves, including emergency and load ones; 5) consumption of excess electric power generated by NPP during night load dips and provision of conditions for their optimal operation.

Currently, hydro-accumulation systems and, above all, HAPS occupy the dominant position (over 96\%) in the NPP market for large energy. The total capacity of the HAPS in the world is more than $150 \mathrm{GW}$ ). In the forecasts of the agency IRENA is expected to increase the capacity of PSPS to 325 GW by 2030 [16].

The unique peculiarity of the HAPS lies not only in the physical replacement of the volumes of fuel consumed and the optimization of the operating modes of the basic power plants, but also in the significant increase in the reliability of the functioning of the energy system due to the provision of system services.

Nowadays, only the Zagorskaya HAPS in the ECO Center is operated in Russia (with an installed capacity of 1,200 MW and a number of hours of use of about 4,000 hours per year) and the Zelenchukskaya hydroelectric power station-HASP with an installed capacity of $140 \mathrm{MW}$ in the ECO South.

The further development of the HAPS in Russia is planned in the "Program for the development of hydropower in Russia until 2030 and for the future until 2050," which was prepared on the instructions of PJSC RusHydro. In the target scenario of the proposed hydraulic construction program until 2050, it is planned to introduce $12.3 \mathrm{GW}$ through the construction of four HAPS in the European part of the country.

In Uzbekistan, the option of building a $200 \mathrm{MW}$ Khozhdikent is being considered on the basis of the Khozhdikent hydroelectric power station in operation. However, these plans have not yet been implemented for various reasons.

With the shortage of maneuverable capacities in the power system, due to the HAPS pumping mode and a change in the operating mode of large pumping stations (PS), it is possible to increase the night base load in the power system, which will allow introducing new capacities at nuclear power plants (which is especially relevant for Uzbekistan, in connection with the plans for the construction of nuclear power plants), change the structure of generating capacities, as well as increase the possibility of providing system services. For an adequate economic assessment of these regime opportunities, it became necessary to develop a methodology for the energy and economic assessment of NPP, including HAPS, in modern economic conditions.

\section{Methods and Materials}

In order to assess the effectiveness of HAPS participation in electricity markets, including in Russia and Uzbekistan, taking into account the provision of regime and system services and obtaining the greatest profit and maximum system effect, an economic and mathematical model of HAPS operation modes in the power system was developed [19], which provides for the possibility of introducing a two-rate tariff and payment for system services. Only this approach makes it possible to ensure the effectiveness of the construction of the HAPS, as evidenced by the foreign experience of the HAPS (PSPP). The results of calculations using this model show [20] that, taking into account surcharges for system effects, the weighted average tariffs for PSPP should be in the range of 1300 to $3000 \mathrm{rubles} / \mathrm{MW} \cdot \mathrm{h}$ (41.06 - (94.76 $\$ / \mathrm{MW}-\mathrm{h}$ ) and fall into the confidence interval from 1650 to 3850 rubles/ MW.h. (51.1-121.6 \$/MW-h) according to domestic and dawn electric power markets (USA, Germany, France, etc.) [20]. With a ratio of basic and peak tariffs of 1:6, the efficiency of the HAPS can be ensured, while the discounted payback period is about 12 years.

According to the results of the study, conclusions were drawn: 1) in order for the construction of the HAPS to be effective, electricity tariffs for the PSPP should be two rates (day-night), 2) it was necessary to take into account the surcharge for working in modes that ensure system-wide reliability, the surcharge for saving organic types of the top-tier at TPP and reducing $\mathrm{CO}_{2}$ emissions.

Taking into account these factors will increase the size of guaranteed profits at the HAPS and will provide an incentive for investments in the construction and modernization of the HAPS and increase the efficiency of the energy system as a whole.

Studies initiated by the authors as early as 1995 [21] and later [5,17,19] showed that hydroelectric power stations with reservoirs can also be considered as NPP for renewable energy, providing balance and reserve in combination with other types of energy. With the help of the water pool of the hydroelectric power station, it is possible to generate time-variable production from wind or solar power plants by accumulating water. The power complex of HPS-WPS or HPS-SPS allows without loss to store the generated WPS or SPS electric energy in the form of potential water energy in the reservoir and convert it back through HPS units in the necessary time. Thus, unlike HAPS, there is no loss in the conversion and accumulation of renewable energy (REE resource electric energy, electric energy - potential water energy) and hydraulic storage efficiency in such an energy complex is $92-95 \%$. Another effect when creating such an energy complex is that it is possible to guarantee the return of energy from the WPS or SPS at the required intervals of time and the predicted participation in the coverage of the load schedule. 


\section{Results and discussion}

Figure 4 shows the results of calculations of the daily operation mode using the example of the Volzhskaya HPS-Volgograd WPS power complex for cases when only the Volzhskaya HPS and the HPS-WPS power complex with a wind farm capacity of $600 \mathrm{MW}$ are operating [17]. The creation of the energy complex ensured an increase in the adjustment range to 1970 MW (by 20\%) and a guaranteed maximum of capacity to $2386 \mathrm{MW}$ (by $12 \%$ ).

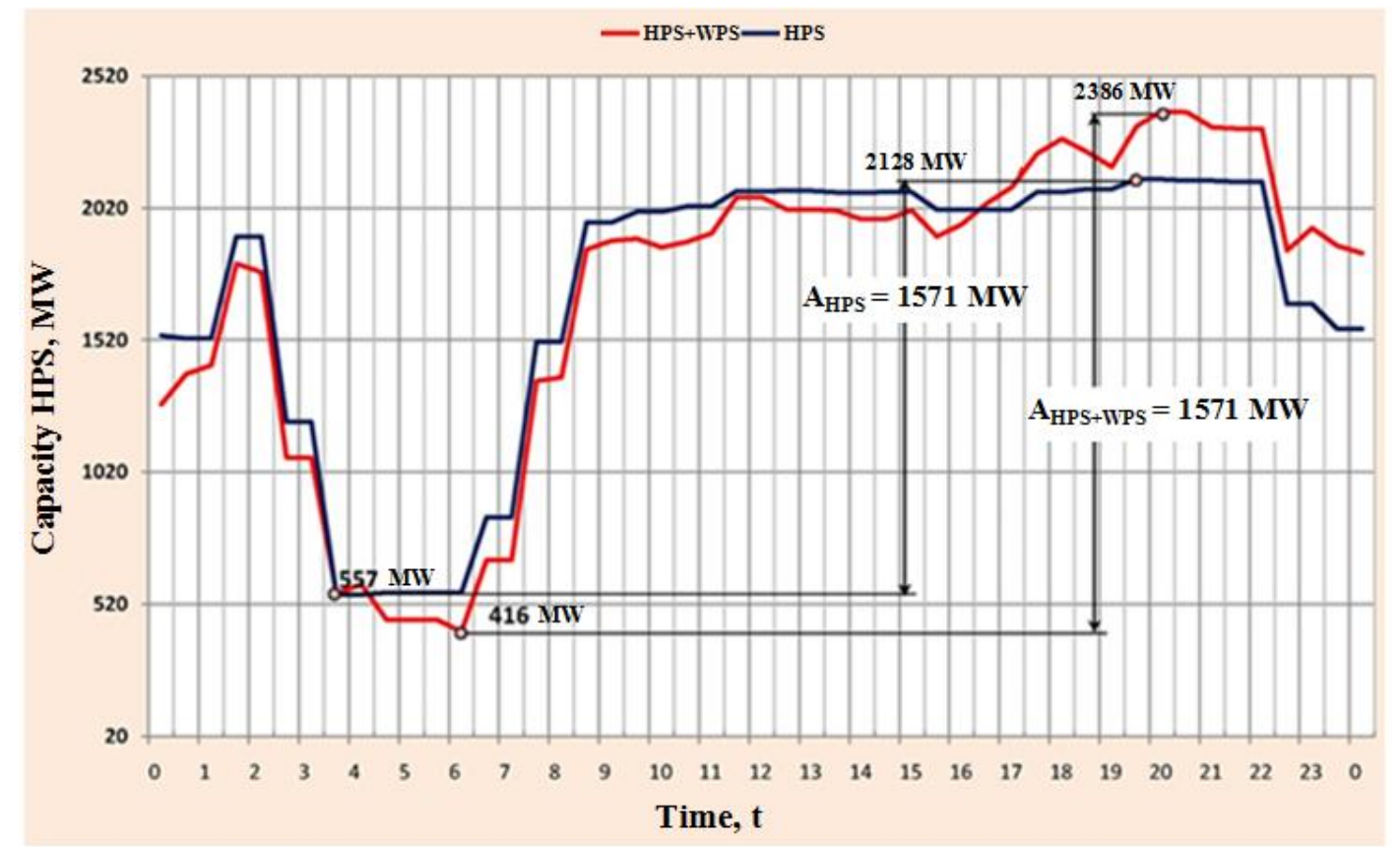

Fig 4. Daily mode of operation of HPS( $(-)$ ) and power Complex of HPS and WPP ( $\square$ ) for December of the average year

For the energy system, the energy complex acts as a single territorial-regional-energy facility with the provision of control over the operation of hydroelectric power stations and high power plants and general participation in energy supplies to Wholesale Market of Power and Energy. This approach allows you to reduce operating costs, provide system services, guarantee the production of wind farms for the upcoming period, directly deliver energy to the consumer. The possibility of establishing such complexes on the basis of existing hydroelectric power stations and water storage facilities without additional flooding gave economic advantages over any other means of energy management.

In the Republic of Uzbekistan, one of the possible directions for improving the maneuverability of EPS may be the use of large PS for accumulating hydraulic energy.

In the works of the authors $[22,23,24]$, the issues of the PS training in increasing the maneuverability of the EPS were investigated, the results of which so far indicated that pumping stations could be successfully used in two versions: in the PS mode - the HAPS and as a consumer - the regulator during the night load minima in the EPS.

Let us consider the possibilities of using PS working in the economic and economic sector of the Republic of Uzbekistan in the mode of consumption regulator.
According to the Ministry of Water Management of the Republic, the total installed capacity of the PS is 3700 MW. Many PS operating in the growing season are operated in full working capacity 3... 4 months per year (mainly May - August months) with highly variable water consumption and slightly changing pressures. PS of year-round operation are operated, which outside irrigation time serve to fill reservoirs. The medium utilization factor of PS installed power does not exceed $40 \ldots 60 \%$. In this regard, during the year the operating capacity of the PS is $1500 \ldots 2700$ MW.

As an example, we take the operating capacity of the PS $1500 \mathrm{MW}$ and assume that $50 \%$ of them, i.e. $750 \mathrm{MW}$, are profitable to use in the mode of the consumer - regulator. The PS operation mode can be illuminated on the daily load chart of the EPS of the Republic for 17.06.2020 year (Figure 5).

To fill the night load dips, the power system will fully deliver $750 \mathrm{MW}$ of power to pumping stations, which in a forced mode will supply the irrigation network and hydroelectric facilities with an appropriate volume of water from $1^{00}$ night for about 8 hours, consuming $5300 \mathrm{MW} \cdot$ hours of energy for this purpose. Starting from about 9 hours to $22^{30}$ PS will gradually be shut down, and their power is reduced to $750 \mathrm{MW}$ to reduce the balance of daily consumed energy (5300 MW · hours) and, therefore, the volume of water supplied. 
From the graph given in Figure 5 it can be seen that as a result of PS inclusion in the process of the consumer-regulator, the non-uniformity coefficient of the load graph changes from 0.77 to 0.91 , which is a sign that the number of mode switches of turbo-units is sharply reduced, which leads to significant fuel economy and increases the life cycle of the equipment, which is confirmed by the results of other studies [9,11,14].
Currently, the issues of regulating the flow rate of water supplied by pumping units, starting and stopping

electric motors have been quite successfully studied and there are reliable, economical methods for controlling the operating modes of the PS, and in this regard it can be assumed that the use of the above method should not raise special questions [25].

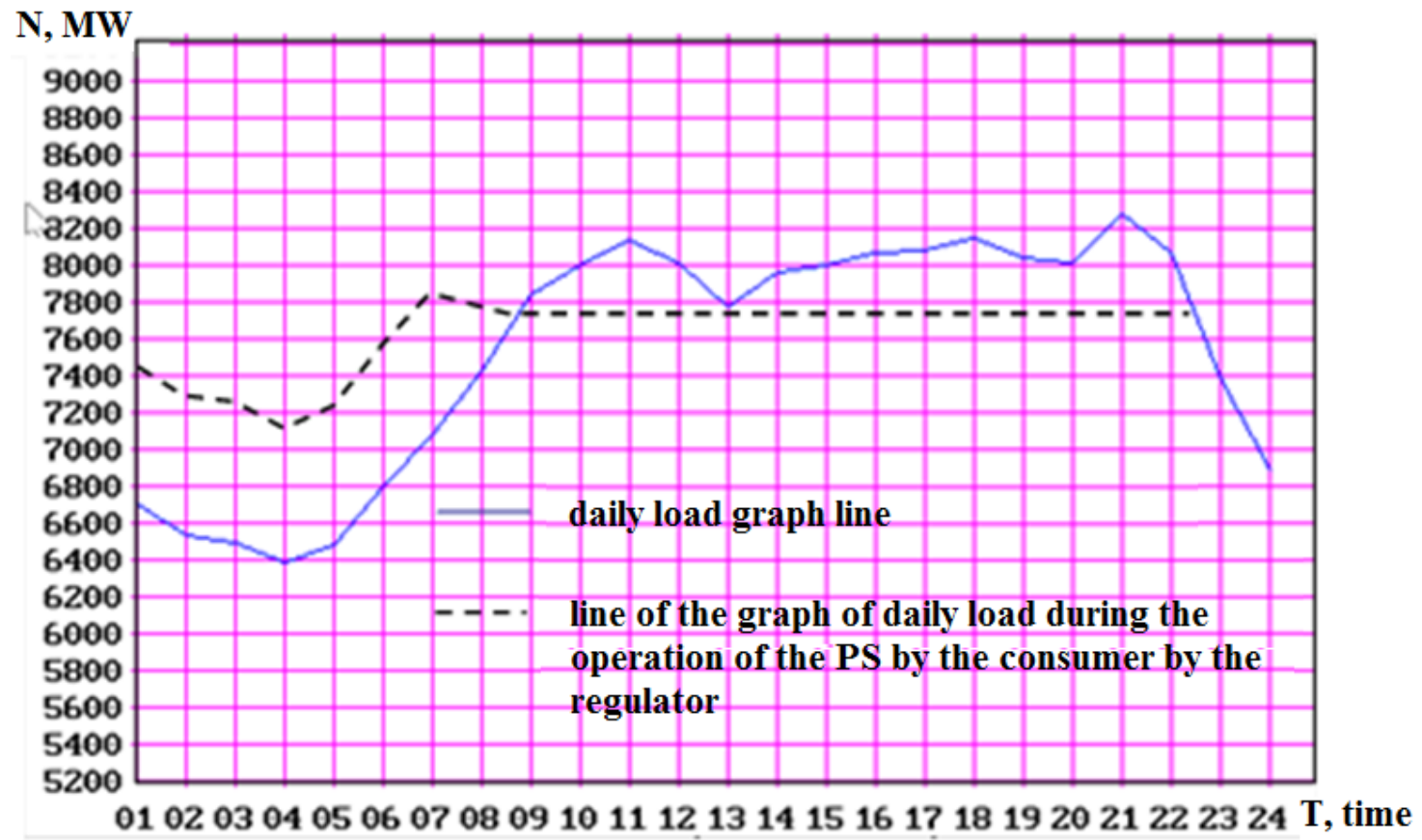

Fig. 5. Daily load schedule of the EPS of the Republic of Uzbekistan (17.06.2020)

In order to implement the above procedure of EPSPS operation, it will probably be necessary to create an inter-department coordination and computational control center, the function of which is to determine the operating modes and control all pumping stations involved in regulating the daily load schedule of EPS. The Centre would coordinate actions between households, develop and implement a plan, schedule for the operation of facilities - consumers and producers of energy, and resolve economic issues.

\section{Conclusion}

1. Under the conditions of the adopted Energy Development Programs in the Russian Federation and the Republic of Uzbekistan related to the increase in the share of small-scale power plants, including NPP, WPS, SPS, in the work, measures were considered to increase the efficiency of HAPS, as well as the use of storage systems of hydroelectric power stations and pumping stations.

2. To increase economic efficiency, the HAPS should introduce differentiated (day-night) reefs, work allowances in modes that ensure system reliability, a surcharge for saving organic fuels at thermal power plants and reducing $\mathrm{CO}_{2}$ emissions, which will increase the efficiency of the energy system.
3. The results of the study showed that hydroelectric power plants with water storages can be considered as a battery for renewable energy, providing smoothing of time-variable production from wind or solar power plants. The creation of the HPS-RES power complex allows you to reduce operating costs, provide system services, guarantee the production of RES for the upcoming period, directly deliver energy to the consumer.

4. It has been shown that the use of PS in the consumer mode - regulator by further increasing their power during the nightly load minimums in the EPS and, as a result, reducing the output power in the peak load hours with respect to the balance of energy and the volume of water supplied, allows to significantly close the load schedule, reduces the number of mode switches of turbine units, which leads to significant fuel economy and increases the life cycle of the equipment.

\section{References}

1. Electricity storage and renewables: Costs and markets to 2030.

http://www.irena.org/publications/2017/Oct/Electricity -storage-and-renewables-costs-and-markets

2. Electric Power Research Institute: Electricity Energy Storage Technology Options. A White Paper Primer on 
Applications, Costs, and Benefits http://large.stanford.edu/courses/2012/ph240/doshay1/

docs/EPRI.pdf

3. International Energy Agency: Technology Roadmap on Energy Storage, 2014.

https://www.iea.org/publications/freepublications/ publication/Technology RoadmapEnergystorage.pdf. 4. European commission directorate-general for energy. DG ENER Working Paper. The future role and challenges of Energy Storage. https://ec.europa.eu/energy/sites/ener/files/ energy storage.pdf.

5. Elistratov V.V. Renewable energy. St. Petersburg: Publishing house of Polytechnic. University, 2016. $424 \mathrm{p}$.

6. Vasiliev Yu.S., Pretro G.A. Pumped storage power plants/Textbook. LPI. 1984 .-- 76 p.

7. Electrical Energy Storage. IEC white paper; December 2011.

http://www.iec.ch/whitepaper/pdf/iecWPenergystorage-LR-en.pdf.

8. V.V. Zubarev Accumulating power plant and uses them as of a power systems. $-\mathrm{M}$.: Informenergo, ser.4, issue 4, 34-38 (1986)

9. V.Y. Sinyugin, V.I. Magruk, Rodionov V.G. Hydroaccumulative power plants in modern electric power industry / - M.: ENAS, 352 (2008)

10. Report on the functioning of the UES of Russia in 2019.

http://soups.ru/fileadmin/files/company/reports/disclos ure/2020/ups rep2019.pdf.

11. L.B. Scheinman, Accumulating power plants/ Under. ed. - M.: Energy, 184 (1978)

12. Energy storage - packing some power. The Economist. 2011-03-03. Retrieved 2012-03-11; 2012. http://www.economist.com/node/21548495? frsc $=\mathrm{dg} \% 7$ Ca.

13. Paul Denholm, Erik Ela, Brendan Kirby and Michael Milligan. The Role of Energy Storage with Renewable Electricity Generation. Technical Report NREL/TP-6A2-47187 January 2010. 